\title{
Regional Creative Class Agglomeration and Its Impact on Regional Economic Growth: Based on China's Empirical Data
}

\author{
Xin Deng*, Minghua Lin \\ School of Management, Sichuan University of Science \& Engineering, Yibin, China \\ Email: *dengxin06010208@163.com, linminghua@sohu.com
}

How to cite this paper: Deng, X., \& Lin, M. H. (2021). Regional Creative Class Agglomeration and Its Impact on Regional Economic Growth: Based on China's Empirical Data. Open Journal of Business and Management, 9, 1890-1905.

https://doi.org/10.4236/ojbm.2021.94102

Received: June 27, 2021

Accepted: July 20, 2021

Published: July 23, 2021

Copyright $\odot 2021$ by author(s) and Scientific Research Publishing Inc. This work is licensed under the Creative Commons Attribution International License (CC BY 4.0).

http://creativecommons.org/licenses/by/4.0/

(c) (i) Open Access

\begin{abstract}
This paper divides the creative class into cultural and technological creative class. After calculating the development trend of these two types of creative class agglomeration scale in 30 regions of China from 2009 to 2017, this paper uses fixed effect model to empirically analyze the impact of creative class agglomeration scale on the regional economy, and finally puts forward corresponding countermeasures. The results show that: first, on the one hand, from the perspective of evolution, the agglomeration scale of cultural and creative class in 14 regions has not changed, while the other 16 regions shows a development trend of first rising and then falling to the original level, and the agglomeration scale of technological and creative class in most regions has not changed; on the other hand, from the perspective of space, the agglomeration scale of cultural and technological creative class in most regions is always at a medium or low level, and in eastern region is relatively high while that in most western regions is relatively low. Secondly, the agglomeration of cultural and technological creative class has a significant positive impact on regional economic growth, while the latter has a greater impact, but it is not statistically significant.
\end{abstract}

\section{Keywords}

Cultural and Creative Class, Technological and Creative Class, Aggregated Distribution, Regional Economic Growth

\section{Introduction}

The idea of "creative class" put forward by Florida (2002) has been questioned by many scholars (Glaeser, 2004; peck, 2005; Markusen \& Schrock, 2006; Bontje 
\& Musterd, 2009). However, with the advent of the era of creative economy, more and more scholars affirm this proposition and mainly discuss the creative class from the following three aspects: first, some scholars focus on the influencing factors of the agglomeration of the creative class (Ling \& Dale, 2011; You \& Bie, 2017; Batabyal \& Yoo, 2019) and formation mechanism (Zhao et al., 2020); The second is the analysis of the preference of creative class, such as the preference of residential location (Lawton et al., 2013) and the problem of leisure preference (Holm, 2014); the third is the effect brought by the agglomeration of creative class, such as the agglomeration of creative class promotes the regional economic growth (such as Stolarick \& Currid-Halkett, 2013; Florida, 2014; Boschma et al. 2009; Tiruneh, 2014; Batabyal \& Beladi, 2017) can promote local innovation scale (e.g., Aneta and Valerij, 2015) and urban level innovation (Rodríguez-Pose, \& Lee, 2020). It has a direct and indirect effect on regional labor productivity (for example, Florida et al., 2008), promotes regional employment growth (Boschma \& Fritsch, 2007), and has an impact on regional unemployment rate (Stolarick \& Currid-Halkett, 2013) and local innovation policy (Batabyal \& Yoo, 2017).

However, there are still some gaps in the current literature. If some scholars have noticed the differences and evolution trend of the scale of creative level agglomeration in different regions of China, as well as the impact on regional economic growth, it still needs to be further improved (Zhang \& Zhao, 2017). In addition, the current research on the impact of creative industry agglomeration on regional economic growth is more from the perspective of the whole creative industry, rarely from the perspective of different types of creative industry agglomeration. But in fact, talents engaged in cultural creativity and technological creativity play completely different roles in the process of economic growth (Florida, 2002), and their impact on regional economic growth may be different.

Therefore, in order to further fill the gaps in the current literature, this study will focus on solving the following three problems: first, whether there are differences in the scale of cultural, scientific and Technological Creative Class agglomeration in time and space, and how its evolution trend is; Second, whether the cultural and technological creative class will have an impact on China's regional economic growth; Third, whether there are significant differences in the intensity of China's regional economic growth between the cultural class and the technological and creative class.

Therefore, this study will focus on solving the following three problems : First, whether the agglomeration scale of cultural and technological and creative class in China is different in time and space, and what is the evolution trend; second, whether the cultural creative class and technological creative class will have an impact on China's regional economic growth; third, whether there is a significant difference between the cultural and the technological and creative class in the intensity of China's regional economic growth.

The structure of this paper is as follows: the second part mainly describes the 
classification basis of the Cultural and Technological Creative Class at the provincial level in China, as well as the status quo of their agglomeration and distribution; The third part is an empirical study, which not only tests the economic impact intensity of the regional creative class on China's provinces, but also further tests whether there are differences between the regional cultural creative class and the Regional Technological Creative Class on the economic impact intensity of China's provinces. The fourth part mainly puts forward relevant suggestions for the current situation of the agglomeration and distribution of creative class and the intensity of economic impact. The fifth part is mainly for the deficiencies of this study, put forward further consideration.

\section{Analysis on the Agglomeration of Regional Creative Class}

\subsection{The Definition of Creative Class}

American scholar Florida (2002) first proposed the concept of "creative class" in his book "the rise of creative class". Through observing the changes of American social structure, Florida finds that a new class, namely "creative class", is gradually rising. The proportion of creative class members in employment has increased from less than $10 \%$ in 1900 to $30 \%$ in 1999. Florida defines the creative class as a working class engaged in "creating meaningful new forms", and further divides the creative class into "core groups" and "innovation experts". Among them, the "core group" consists of "super creative core" groups (scientists and engineers, university professors, poets and novelists, artists, actors, designers and architects), as well as the thought pioneers of modern society (non fiction writers, editors, intellectuals, members of think tanks, analysts and other "opinion makers"). Although there is no clear definition of "innovation expert", it is widely distributed in knowledge intensive industries, such as high-tech industry, financial services industry, law and health care industry and business administration.

Creativity is different from "cultural creativity" and "technological creativity", in which "technological creativity" is also known as technological innovation (Florida, 2002). Lin \& Yang (2014) further pointed out that cultural class refers to giving special symbolic meaning to a certain product/service in the process of conveying ideas and feelings; technological class is the forerunner of cultural class, which improves the production efficiency of products and thus enriches materials. Following this idea, we divide the creative class into cultural and creative class and technological and creative class. Among them, the cultural and creative class refers to the professionals engaged in news, publishing, radio, television, film and television recording and production, culture and art. The technological and creative class mainly refers to the personnel engaged in science and technology, mainly composed of professionals engaged in telecommunications, radio and television and satellite services, Internet and related services, software and information technology services, research and experimental development, professional technology services, science and technology promotion 
and application services.

\subsection{Analysis on the Development Trend of Regional Creative Class Agglomeration}

The scale of talent agglomeration can be measured by the number of all kinds of talents (Zhang, 2008). Therefore, this paper uses the number of the creative talents, that is, the number of creative class, to measure the agglomeration scale of creative class. According to the definition of cultural and creative class and technological and creative class in this paper, and corresponding to China's national economic industry classification (revised in 2019), considering the availability of data, this study uses the sum of the number of urban employees in the news and publishing industry, radios, films and televisions recording and production industry, as well as the culture and art industry to measure the agglomeration scale of cultural creative class The total number of urban employees in scientific research and technology services including research and experimental development, professional technology services, science and technology promotion and application services, as well as information transmission, software and information technology services including telecommunications, radio and television and satellite transmission services, Internet and related services, software and information technology services, represents the technological creative class set scale. The data of cultural and creative class and technological and creative class in different regions are from the 2010-2018 China population and Employment Statistical Yearbook.

\subsubsection{Analysis of Regional Cultural and Creative Class Agglomeration} According to the natural discontinuity segmentation method, we divide the scale of cultural and creative class into three categories: high scale, medium scale and low scale. This paper selects 2009, 2013 and 2017 as the observation time points to analyze the spatial and temporary distribution of the agglomeration scale of cultural and creative class, as shown in Figure 1. There is no change in the scale of cultural and creative agglomeration of 14 regions in the above three observation time points. Among them, Beijing is a high agglomeration area, Liaoning, Hebei, Shanxi, Shaanxi, Sichuan, Hubei and Hunan are medium agglomeration areas, Qinghai, Gansu, Ningxia, Guizhou, Hainan and Chongqing are low agglomeration areas; the scale of cultural and creative agglomeration of 5 regions is low in 2009, the scale of cultural and creative class increased from medium scale to high scale, and then decreased to the original level, which were Shandong, Jiangsu, Zhejiang, Henan and Guangdong; in Xinjiang, Inner Mongolia, Jilin, Heilongjiang, Anhui, Guangxi, Yunnan, Jiangxi, Fujian, Tianjin and Shanghai, the scale of cultural and creative class increased from low scale in 2009 to high level in 2013 after 2017, it rapidly fell back to the low agglomeration level.

To sum up, from the perspective of evolution, nearly half of the regions have no change in the scale and level of cultural and creative class agglomeration, while the scale and level of cultural and creative class agglomeration in other 


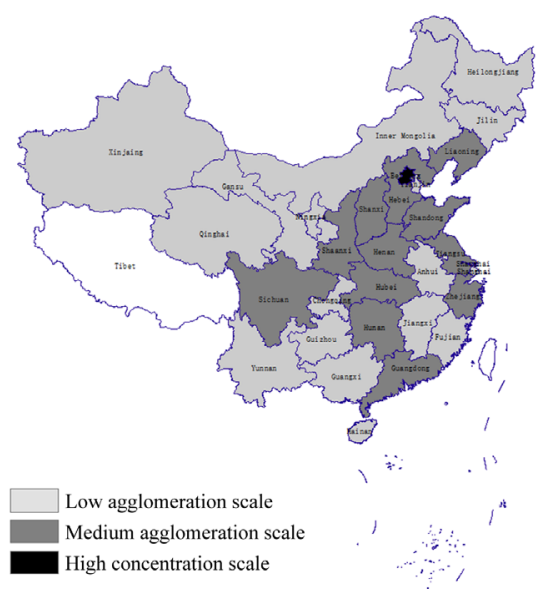

(1) 2009

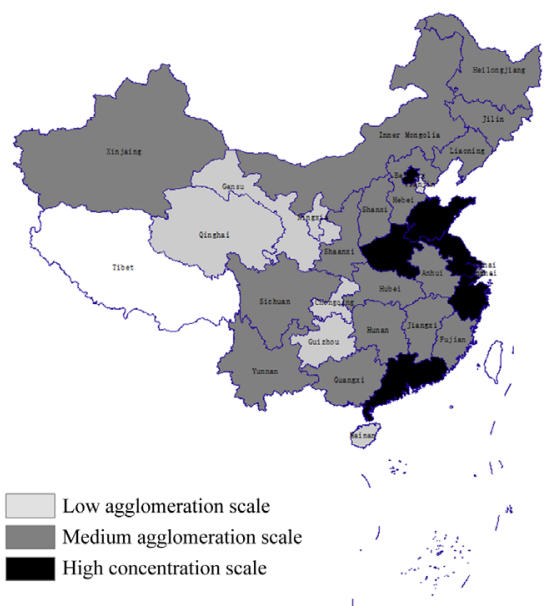

(2) 2013

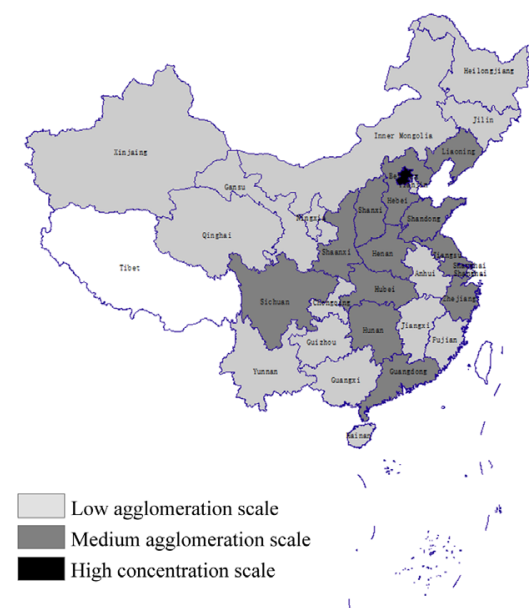

(3) 2017

Figure 1. Spatial and temporal distribution of the scale of cultural and creative class agglomeration $(2009,2013,2017)$.

regions shows a trend of first rising and then falling back to the original level; from the perspective of space, the scale and level of cultural and creative class agglomeration in the eastern region as a whole has been relatively higher, and the vast majority of them have been in the eastern region The agglomeration scale of cultural and creative class in the western region continues to be at a low level.

\subsubsection{Analysis of the Agglomeration of Regional Technological and Creative Class}

According to the natural discontinuity segmentation method, the agglomeration scale of technological and creative class is divided into three categories: high agglomeration scale, medium agglomeration scale and low agglomeration scale. Similarly, take 2009, 2013 and 2017 as the observation time points to analyze the spatial and temporary distribution of the agglomeration scale of technological and creative class, as shown in Figure 2. Among the 24 regions, only one region in Beijing is a high-scale region, four regions in Jiangsu, Zhejiang, Guangdong and Shanghai are medium-scale regions, and Heilongjiang, Jilin, Inner Mongolia, Hebei, Tianjin, Shanxi, Ningxia, Gansu, Qinghai, Xinjiang, Yunnan, Guizhou, Guangxi and other regions are medium-sized regions the 19 regions of Chongqing, Hunan, Jiangxi, Fujian, Anhui and Hainan are always in the low agglomeration scale regions; the hierarchical scale regions of 6 regions show a downward trend, among which Liaoning, Shandong and Sichuan have decreased from the medium agglomeration scale in 2013 to the low agglomeration scale in 2017; Henan, Shaanxi and Hubei have all decreased from the medium agglomeration scale in 2009 to the low agglomeration scale in 2013 it remains the same after level.

It can be seen that from the perspective of evolution, the scale level of technological and creative class agglomeration in most regions remains basically unchanged, while the scale level of a few regions decreases, and a few regions recover to the original scale after the decline; from the perspective of space, the 


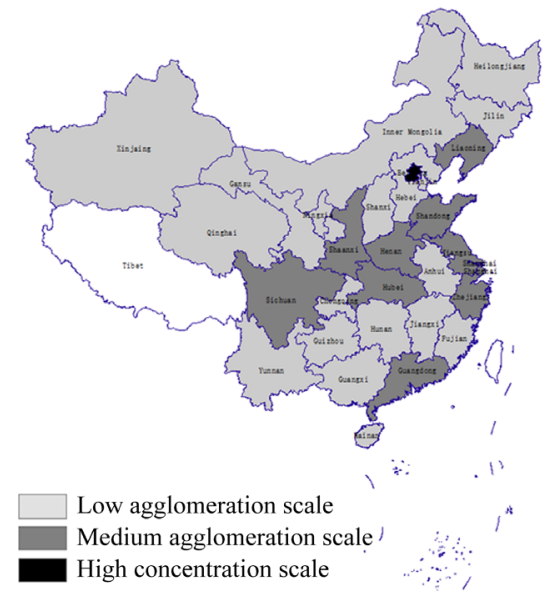

(1) 2009

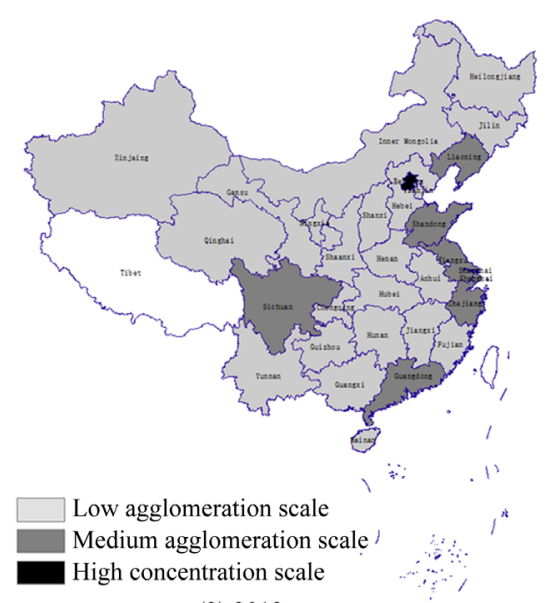

(2) 2013

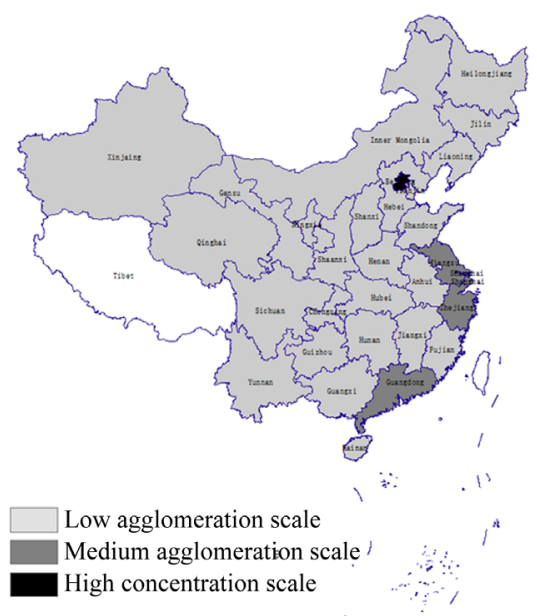

(3) 2017

Figure 2. Spatial and temporal distribution of agglomeration scale of technological and creative class $(2009,2013,2017)$.

regions with relatively high scale of technological and creative class agglomeration are mainly distributed in the eastern region, especially in the central and western regions the scale of technological and creative class agglomeration is the lowest in the economically backward areas, and it is gradually converging to the eastern economically developed areas.

\subsection{A Comprehensive Analysis of the Agglomeration of Regional Cultural Creativity and Technological Creativity}

Furthermore, based on the above classification of the agglomeration scale level of the cultural and creative class and the technological and creative class, taking the agglomeration scale level of the technological and creative class as the horizontal axis and the agglomeration scale level of the cultural and creative class as the vertical axis, the agglomeration scale level of the regional creative class is divided into nine types, as shown in Figure 3.

We select 2017 as the time point to comprehensively observe which creative class agglomeration type of China's 30 regions belong to, as shown in Figure 3. It can be seen that only Beijing ("BK") belongs to the "double high" creative class gathering area; Jiangsu ("JS"), Zhejiang (“ZJ") and Guangdong (“GD”) are the "double middle" creative class gathering area; Shanghai ('SH") is the low cultural and creative class middle technological and creative class gathering area; Hebei ("HE"), Shanxi (“SX"), Liaoning ("LN"), Hunan ("HN"), Sichuan (“SC"), Shaanxi ("SN"), Shandong (“SD"), Henan ("HA"), Hubei ("HB”) and nine regions are the middle cultural and creative class and low technological and creative class gathering area Tianjin (“TJ”), Inner Mongolia ("IM"), Jilin (“JL"), Heilongjiang (“HL”), Anhui (“AH”), Fujian (“FJ”), Jiangxi (“JX”), Guangxi (“GX”), Hainan (HI”), Chongqing (“CQ”), Guizhou (“GZ”), Yunnan (“YN”), Gansu (“GS”), Qinghai (“QH”), Ningxia (“NX”) and Xinjiang (“XJ”) are the "double low" creative class gathering areas. 


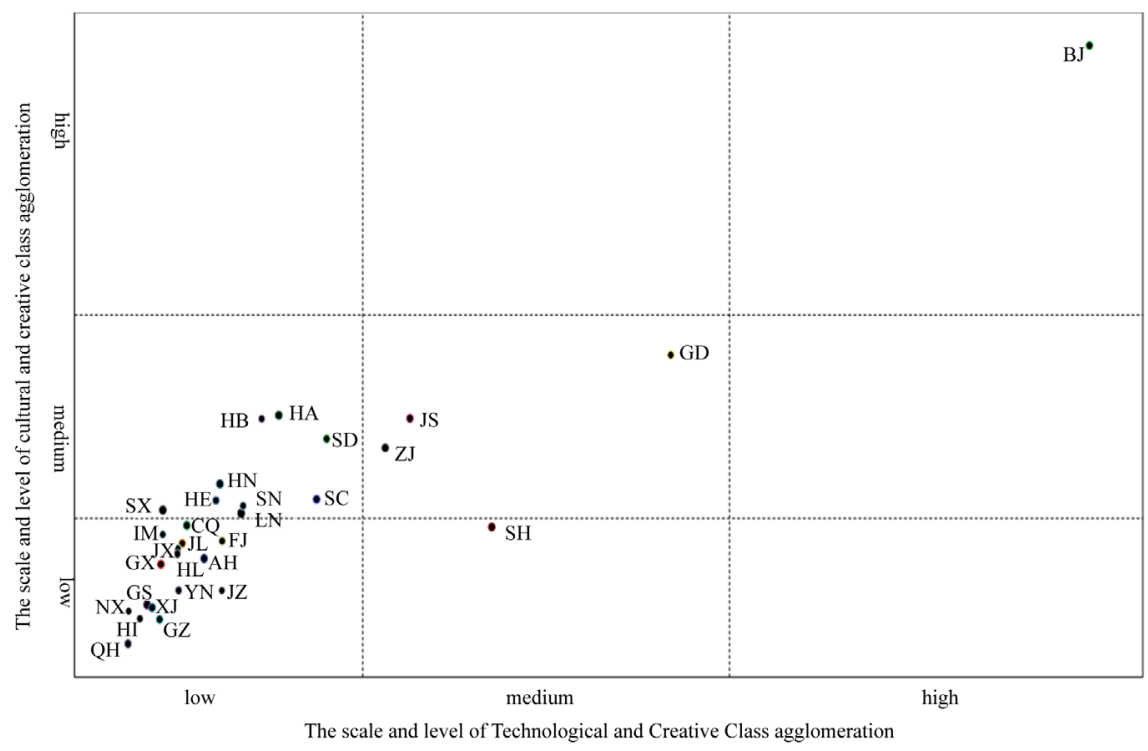

Figure 3. Distribution map of creative class agglomeration in 30 regions of China in 2017.

\section{Analysis of the Impact of Creative Class Agglomeration on Regional Economy}

\subsection{Hypothesis Presentation}

Regional economic growth is driven by the creative class (Florida, 2002: p. 257). Boix-Domenech \& Soler-Marco (2017) pointed out that the higher the proportion of employed people engaged in innovative services, the higher the regional labor productivity. Among them, innovative service industries include publishing, audio-visual, radio and television, software, architecture and engineering, research and development, advertising, design, photography, art and entertainment industries (UNCTAD, 2010). Tao et al. (2019) research results reveal that: the improvement of regional creative industry productivity will drive the overall growth of regional economy. Put another way, provided that a city can attract creative talents, it can promote the economic growth of the region (Jacobs \& Jane, 1985). Zhao et al. (2020) research illustrates that the agglomeration of creative class, the continuous improvement of environmental tolerance and the continuous increase of technology investment have a good explanation for understanding the per capita GDP difference of 279 cities in China.

The majority of the cultural and creative groups choose to gather in some central cities or metropolises (Zhang, 2011). Florida (2002) measured the "Bohemian index" of a region by the number of writers, designers, musicians, actors/directors, painters, sculptors, photographers, dancers and other core cultural and creative classes. Empirical research demonstrates that the higher the index is, the more prosperous the artistic and cultural environment is, the more creative economic achievements can be produced and the more sustainable the development can bring the overall economic growth of the region. Some scholars 
have found that the agglomeration of cultural and creative strata will promote the development of cultural and creative industries in the region, and then promote the economic growth of the region (Power, 2009; Boccella \& Salerno, 2016). Based on this, the following hypotheses are put forward

H1: The agglomeration of cultural and creative classes has a positive impact on regional economic growth.

Sun (2012) pointed out that the computer creative industry supported by computer technology, digital technology, network technology and mass communication technology will produce tremendous economic and social value. Song et al. (2013) also pointed out that in the long run, there is an obvious two-way interactive relationship between technological and creative class, that is, scientific and technological talents, and economic growth. As the most important force to improve total factor productivity, scientific and technological talents have great potential to promote high-quality economic development (Ma et al., 2019). The agglomeration effect of scientific and technological talents caused by the orderly flow and migration of scientific and technological talents has a significant positive interaction mechanism with the development of high-tech industry (Pei, 2018), and has a significant positive impact on regional innovation ability (Zhao et al., 2019), which will ultimately promote the growth of regional economy. Therefore, the following hypotheses are put forward:

H2: The agglomeration of technological and creative class has a positive impact on regional economic growth.

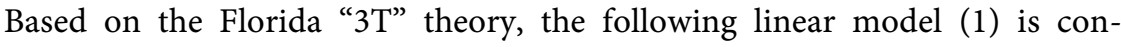
structed:

$$
\mathrm{Y}_{i t}=f\left(\mathrm{CCC}_{i t}, \mathrm{TCC}_{i t}, \mathrm{TOL}_{i t}, \mathrm{TEL}_{i t}, \mathrm{~S}_{i t}\right)
$$

where $i$ means provinces, $i=1,2, \cdots, 30 ; t$ is the year. $\mathrm{Y}$ represents regional economic growth, CCC represents the scale of cultural and creative class agglomeration, TCC represents the scale of technological and creative class agglomeration, TOC represents regional tolerance, TEL represents regional technological level, and $\mathbf{S}$ represents regional industrial structure.

\subsection{Variable Index Selection and Data Sources}

Explained variable: regional economic growth $(\mathrm{Y})$. At present, regional economic growth is generally measured by real per capita GDP. Taking 2009 as the base period, the per capita GDP price index is deflated, excluding the factors of price changes. The regional data is from the annual data of provinces from 2009 to 2017 provided by the official website of the National Bureau of statistics.

Core explanatory variables: the scale of cultural and creative class agglomeration (CCC) and the scale of technological and creative class agglomeration (TCC). The specific data comes from the second section of the second part.

Control variables: 1 ) tolerance (TOL). The rate of regional inclusion is measured by the immigration rate of the population of the foreign country, that is, 
the proportion of the floating population who has left the registered residence for more than half a year to the total population of the region. The data of each region comes from China Statistical Yearbook 2010-2018. 2) Technical level (TEC). The technology level of a region is measured by the turnover of the regional technology market. The regional data are from the annual data of provinces from 2009 to 2017 provided by the official website of the National Bureau of statistics. 3) Industrial structure (S). Referring to the method of Wang (2014) for indicators, the proportion of the added value of the tertiary industry in the added value of the secondary industry is used to express the industrial structure. The regional data are from the annual data of provinces from 2009 to 2017 provided by the official website of the National Bureau of statistics.

In order to weaken the influence of heteroscedasticity, all indexes were logarithmically processed. Restricted by availability of data, we finally selected 30 provinces (municipalities, autonomous regions) in China from 2009 to 2017, except Tibet, Hong Kong, Macao and Taiwan, as the sample data. The basic characteristics of each variable are shown in Table 1.

Specifically, the logarithm of per capita GDP is 9.303-11.91, the average is 10.554 , and the standard deviation is 0.512 , which indicates that the economic development level of different provinces in China is quite different. In addition, for the level of agglomeration of creative class, the logarithm of the level of agglomeration of cultural creative class is $8.569-11.968$, with an average of 10.396 and a standard deviation of 0.661 ; The logarithm of the agglomeration level of the technological creative class is $9.395-11.831$, the average is 11.831 , and the standard deviation is 0.872 , which further shows that the agglomeration distribution of the cultural creative class and the technological creative class in different provinces is quite different.

\subsection{Correlation Test}

In order to check whether the model has a multicollinearity problem, we need to further test the correlation. As shown in Table 2, most of the correlation coefficient among variables are less than 0.7 , and the maximum test result of variance expansion factor (VIF) is 7.02, which is less than 10 , so the model does not have multicollinearity problem.

Table 1. Description statistics of main variables.

\begin{tabular}{cccccc}
\hline variable & Number of observation & mean & std & $\min$ & $\max$ \\
\hline LNY & 270 & 10.554 & 0.512 & 9.303 & 11.910 \\
LNCCC & 270 & 10.396 & 0.661 & 8.569 & 11.968 \\
LNTCC & 270 & 11.831 & 0.872 & 9.395 & 11.831 \\
LNTOL & 270 & -1.790 & 0.672 & -4.713 & 0.926 \\
LNTEC & 270 & 4.171 & 1.745 & -0.580 & 8.409 \\
LNS & 270 & -0.043 & 0.390 & 1.444 & -0.694 \\
\hline
\end{tabular}


Table 2. Correlation analysis of variables.

\begin{tabular}{cccccccc}
\hline Correlation & LNY & LNCCC & LNTCC & LNTOL & LNTEC & LNS & VIF \\
\hline LNY & 1.000000 & & & & & & \\
LNCCC & 0.347652 & 1.000000 & & & & & 4.79 \\
LNTCC & 0.522138 & 0.876332 & 1.000000 & & & & 7.02 \\
LNTOL & 0.643885 & 0.133799 & 0.291701 & 1.000000 & & & 1.30 \\
LNTEC & 0.622081 & 0.648737 & 0.781182 & 0.342023 & 1.000000 & & 2.69 \\
LNS & 0.434757 & 0.131884 & 0.277020 & 0.379259 & 0.302341 & 1.000000 & 1.25 \\
\hline
\end{tabular}

\subsection{Empirical Analysis}

\subsubsection{Result Analysis}

Because the Hausman test of each model was significant $(P=0.000)$, the original hypothesis was rejected, so the fixed effect model was selected. The model (1) in Table 3 is the basic model. According to the stepwise regression method, the control variable tolerance (LNTOL), the technology level (LNTEC) and industrial structure (LNS) are added to the basic model to get the models (2) - (4).

It can be seen from Table 3 that after gradually adding control variables, as shown in model (4), the agglomeration scale of cultural and creative class (LNTCC) and technological and creative class (LNTEC) have a significant positive impact on regional economic growth. Among them, the elastic coefficient of the scale of cultural and creative class agglomeration is 0.126 , that is, the scale of cultural and creative class agglomeration increases by $1 \%$, and the regional economic growth will increase by 0.126 percentage points; the elastic coefficient of the scale of technological and creative class agglomeration is 0.171 , that is, the scale of technological and creative class agglomeration increases by $1 \%$, and the regional economic growth will increase by 0.171 percentage points. This means that hypothesis 1 and hypothesis 2 is verified. In addition, because the regression coefficient of the agglomeration scale of the technological and creative class $(0.171)$ is greater than that of the cultural and creative class (0.126), it means that the former plays a greater role in promoting regional economic growth. However, whether there is a statistically significant difference between the two still needs to be further verified.

For the control variables, the regression results of model (4) show that regional tolerance, technological level and industrial structure have a significant positive impact on regional economic growth.

Furthermore, we use Wald test to explore whether there is statistical difference in the impact of the agglomeration scale of cultural and creative class and technological and creative class on economic growth, as shown in Table 4. The results represents that the Wald test can not reject the original hypothesis at either the $10 \%$ or $5 \%$ significance level, and it can be took into account that the constraint is reasonable. Therefore, although the agglomeration of technological and creative class has a stronger promoting effect on regional economic growth 
Table 3. Regression results.

\begin{tabular}{|c|c|c|c|c|}
\hline Variables & (1) & (2) & (3) & (4) \\
\hline LNCCC & $\begin{array}{l}0.269^{*} \\
(1.816)\end{array}$ & $\begin{array}{l}0.236 \\
(1.693)\end{array}$ & $\begin{array}{l}0.107 \\
(1.266)\end{array}$ & $\begin{array}{l}0.126^{* *} \\
(2.258)\end{array}$ \\
\hline LNTCC & $\begin{array}{l}0.408^{* * *} \\
(7.436)\end{array}$ & $\begin{array}{l}0.359^{* * *} \\
(6.268)\end{array}$ & $\begin{array}{l}0.210^{* * *} \\
(5.095)\end{array}$ & $\begin{array}{l}0.171^{* * *} \\
(5.327)\end{array}$ \\
\hline LNTOL & & $\begin{array}{l}0.147^{\star * *} \\
(4.044)\end{array}$ & $\begin{array}{l}0.047^{\star \star} \\
(2.400)\end{array}$ & $\begin{array}{l}0.079^{* * *} \\
(3.335)\end{array}$ \\
\hline LNTEC & & & $\begin{array}{l}0.254^{* * *} \\
(9.805)\end{array}$ & $\begin{array}{r}0.170^{\star * *} \\
(5.562)\end{array}$ \\
\hline LNS & & & & $\begin{array}{l}0.524^{* * *} \\
(5.376)\end{array}$ \\
\hline $\mathrm{C}$ & $\begin{array}{l}2.928^{\star} \\
(2.022)\end{array}$ & $\begin{array}{l}4.120^{* * *} \\
(2.791)\end{array}$ & $\begin{array}{l}5.975^{* * *} \\
(6.545)\end{array}$ & $\begin{array}{l}6.677^{* * *} \\
(11.451)\end{array}$ \\
\hline $\mathrm{N}$ & 270 & 270 & 270 & 270 \\
\hline $\mathrm{R}^{2}$ & 0.304 & 0.373 & 0.729 & 0.836 \\
\hline $\mathrm{F}$ & 38.860 & 46.361 & 144.192 & 138.787 \\
\hline$P$ & 0.000 & 0.000 & 0.000 & 0.000 \\
\hline
\end{tabular}

Note: ${ }^{*} P<0.1,{ }^{* *} P<0.05,{ }^{* * *} P<0.01, \mathrm{t}$ value in brackets.

Table 4. Wald test with coefficient constraint.

\begin{tabular}{cccc}
\hline Test Statistic & Value & $\mathrm{df}$ & Probability \\
\hline t-statistic & -0.779714 & 235 & 0.4363 \\
F-statistic & -0.607954 & $(1,235)$ & 0.4363 \\
Chi-square & -0.607954 & 1 & 0.4356 \\
\hline
\end{tabular}

Null Hypothesis: $\mathrm{C}(1)=\mathrm{C}(2)$.

than that of cultural and creative class, there is no significant difference between them.

\subsubsection{Robustness Test}

Wang et al. (2016) believe that the robustness test can be carried out by replacing the core explanatory variables or changing the sample range. Therefore, after excluding Beijing, Tianjin, Shanghai and Guangdong, this paper selects the remaining 26 regions from 2009 to 2017 as samples to test the robustness. The regression results are shown in Table 5. According to the results of Hausman test, we still use the fixed effect model. It can be seen that the regression results of robustness in Table 5 are basically consistent with those in Table 3, indicating that they have passed the robustness test. 
Table 5. Robust regression results.

\begin{tabular}{|c|c|c|c|c|}
\hline Variables & (1) & (2) & (3) & (4) \\
\hline \multirow{2}{*}{ LNCCC } & 0.220 & 0.182 & 0.087 & $0.124^{*}$ \\
\hline & $(1.487)$ & $(1.343)$ & $(0.984)$ & (2.034) \\
\hline \multirow{2}{*}{ LNTCC } & $0.398^{* * *}$ & $0.326^{\star * *}$ & $0.207^{* * *}$ & $0.177^{* * *}$ \\
\hline & (6.433) & $(4.950)$ & $(4.657)$ & $(4.869)$ \\
\hline \multirow{2}{*}{ LNTOL } & & $0.168^{\star \star \star}$ & $0.055^{\star *}$ & $0.083^{* * *}$ \\
\hline & & $(4.131)$ & $(2.512)$ & (3.085) \\
\hline \multirow{2}{*}{ LNTEC } & & & $0.247^{* * *}$ & $0.166^{* * *}$ \\
\hline & & & $(9.397)$ & (5.286) \\
\hline \multirow{2}{*}{ LNS } & & & & $0.526^{* * *}$ \\
\hline & & & & (5.131) \\
\hline \multirow{2}{*}{$\mathrm{C}$} & $3.521^{* *}$ & $5.066^{* * *}$ & $6.277^{* * *}$ & $6.677^{* * *}$ \\
\hline & $(2.375)$ & $(3.350)$ & $(6.440)$ & $(9.876)$ \\
\hline $\mathrm{N}$ & 234 & 234 & 234 & 234 \\
\hline $\mathrm{R}^{2}$ & 0.255 & 0.343 & 0.707 & 0.823 \\
\hline $\mathrm{F}$ & 27.021 & 40.834 & 121.793 & 107.461 \\
\hline$P$ & 0.000 & 0.000 & 0.000 & 0.000 \\
\hline
\end{tabular}

Note: ${ }^{*} P<0.1,{ }^{* *} P<0.05,{ }^{* *} P<0.01, \mathrm{t}$ value in brackets.

\section{Conclusion}

From the perspective of time and space, this paper analyzes the development trend and current situation of the agglomeration scale of cultural and technological creative classes in 30 regions of China from 2009 to 2017, and subsequently uses the fixed effect model to explore the impact of the agglomeration of cultural and technological creative classes on regional economic growth. The results appear that:

On the one hand, from the perspective of evolution, the scale and level of cultural and creative class agglomeration in 14 regions have not changed, while the scale of cultural and creative class agglomeration in the other 16 regions has shown a trend of first rising and then falling to the original level, and the scale and level of technological and creative class agglomeration in most regions has always remained unchanged; on the other hand, from the perspective of space, the scale and level of cultural and creative class agglomeration in most regions has not transformed the level of agglomeration scale of cultural and technological creative class in the eastern region is relatively high, while that in most western regions is relatively low.

On the other hand, the agglomeration of cultural and technological creative classes can significantly promote regional economic growth. Although the latter has a greater impact on China's regional economic growth, it has not reached a 
statistically significant difference.

Based on the above findings, we believe that for the "double high" creative class cluster area, in other word Beijing, although the policy of the creative class in this area is relatively sound, it still needs to be further improved. It should be oriented to attract some types of creative class and how to better retain and attract these creative class. For Jiangsu, Zhejiang and Guangdong, the policy of creative class should be improved as far as the "double middle" creative class gathering areas are concerned, these areas should consider whether to give priority to the cultural and creative class or the technological and creative class in the design and improvement of the creative class's policy in combination with the local conditions; for Tianjin, Inner Mongolia, Jilin, Heilongjiang, Anhui, Fujian, Jiangxi, Guangxi, Hainan, Chongqing, Guizhou, Yunnan, Gansu, Qinghai, Ningxia and Xinjiang, "double low" creative class gathering areas should be divided into two groups As far as the creative class gathering area is concerned, the government should take "cultivating and retaining" the local creative class as the guidance in the policy-making of creative class, especially in the western region should focus on cultivating and retaining the local characteristic cultural creative class (such as intangible cultural heritage inheritors); for Hebei, Shanxi, Liaoning, Shandong, Henan, Hubei, Hunan, Sichuan, Shaanxi "medium low" and Shanghai "low medium" "As far as the creative class cluster area is concerned, it can be combined with the local situation. When formulating the creative class policy, it should be guided by strengthening the status of the "middle" creative class cluster area. Provided that conditions permit, it can promote the transformation of the "middle" creative class cluster area to the "high" creative class cluster area.

\section{Limitations}

The main limitations of this paper are as follows: first, although the concept of creative class was put forward in Florida in 2002, the creative class has been paid more and more attention by the academic circles, limited by the relevant data access, the data of cultural and creative class and technological and creative class in this study is wider than the data pointed to by its connotation, because some industries do not provide the number of professionals, which limits the number of professionals to a certain extent the application scope of the research.

Second, this paper mainly discusses the agglomeration scale level of cultural and technological creative class and its impact on economic growth from the provincial perspective, but it needs further discussion at the municipal or else county level. In addition, the agglomeration mechanism, the path and the influence mechanism of the cultural and creative class and the technological and creative class also need to be further discussed in the future.

Thirdly, this paper starts from 2019. Considering that the latest version of China Statistical Yearbook 2018, which is related to the inclusion index at that time, corresponds to the data of China in 2017, and there are some missing in- 
dicators before 2009, this paper only discusses the impact of the regional creative class on the regional economy from 2009 to 2017. Whether the data after 2017 can also confirm that the agglomeration of regional creative class will also have an impact on the regional economy remains to be further improved and studied.

\section{Acknowledgements}

Thank you very much to my tutor, Mr. Lin. For me, he is not only a guide in learning, but also a good teacher who teaches by words and deeds, and a warm family like my father and brother. This article benefited from the teacher's painstaking revision and patient and delicate explanation, which gave me great help, and finally let me finish this article smoothly.

\section{Funding}

This paper is supported by the Art Project of the National Social Science Fund (No. 16EH196), Zigong Science and Technology Plan Project (No. 2014RK08), and the Project of Sichuan Provincial Department of Education (No. 15SB119).

\section{Conflicts of Interest}

The authors declare no conflicts of interest regarding the publication of this paper.

\section{References}

Aneta, K., \& Valerij, D. (2015). The Creative Class in Poland and Its Impact on Innovation in Polish Regions. Management, 10, 299-314.

Batabyal, A. A., \& Yoo, S. J. (2017). Schumpeterian Creative Class Competition, Innovation Policy, and Regional Economic Growth (pp. 55, 86-97). MPRA Paper. https://doi.org/10.1016/j.cities.2020.102653

Batabyal, A., \& Beladi, H. (2017). Artists, Engineers, and Aspects of Economic Growth in a Creative Region. MPRA Paper. https://doi.org/10.1016/j.econmod.2017.12.013

Batabyal, A., \& Yoo, S. J. (2019). Using Utilitarian and Rawlsian Policies to Attract the Creative Class: A Tale of Two Cities. MPRA Paper. https://doi.org/10.2139/ssrn.3624485

Boccella, N., \& Salerno, I. (2016). Creative Economy, Cultural Industries and Local Development. Procedia-Social and Behavioral Sciences, 223, 291-296. https://doi.org/10.1016/j.sbspro.2016.05.370

Boix-Domenech, R., \& Soler-Marco, V. (2017). Creative Service Industries and Regional Productivity. Papers in Regional Science, 96, 261-279.

https://doi.org/10.1111/pirs.12187

Bontje, M., \& Musterd, S. (2009). Creative Industries, Creative Class and Competitiveness: Expert Opinions Critically Appraised. Geoforum, 40, 843-852. https://doi.org/10.1016/j.geoforum.2009.07.001

Boschma, R. A., \& Fritsch, M. (2007). Creative Class and Regional Growth-Empirical Evidence from Eight European Countries. SSRN Electronic Journal. https://doi.org/10.2139/ssrn.1023869

Boschma, R., Eriksson, R., \& Lindgren, U. (2009). How Does Labour Mobility Affect the 
Performance of Plants? The Importance of Relatedness and Geographical Proximity. Druid Working Papers, 9, 169-190. https://doi.org/10.1093/jeg/lbn041

Florida, R. (2002). The Rise of the Creative Class. New York: Basic Books.

Florida, R. (2014). The Creative Class and Economic Development. Economic Development Quarterly, 28, 196-205. https://doi.org/10.1177/0891242414541693

Florida, R., Mellander, C., \& Stolarick, K. (2008). Inside the Black Box of Regional Development: Human Capital, the Creative Class and Tolerance. Journal of Economic Geography, 8, 615-649.

Glaeser, E. L. (2004). Review of Richard Florida's the Rise of the Creative Class. Regional Science \& Urban Economics, 35, 593-596.

https://doi.org/10.1016/j.regsciurbeco.2005.01.005

Holm, E. (2014). Leisure Choices of the Creative Class. Cities, 41, 38-43. https://doi.org/10.1016/j.cities.2014.05.006

Jacobs \& Jane (1985). Cities and the Wealth of Nations: Principles of Economic Life (1st Vintage Books ed.). Vintage Books.

Lawton, P., Murphy, E., \& Redmond, D. (2013). Residential Preferences of the "Creative Class"? Cities, 31, 47-56. https://doi.org/10.1016/j.cities.2012.04.002

Lin, M. H., \& Yang, Y. Zh. (2014). Creative Product Development Model: Using Cultural Creativity to Boosting Created in China. Beijing: Economic \& Management Publishing House.

Ling, C., \& Dale, A. (2011). Nature, Place and the Creative Class: Three Canadian Case Studies. Landscape \& Urban Planning, 99, 239-247.

https://doi.org/10.1016/j.landurbplan.2010.11.006

Ma, R., Zhang, J., \& Wang, H. W. (2019). Do S \& T Talents Contribute to High-Quality Economic Development of China? Empirical Test Based on Effect of S \& T Talents on TFP. Research on Economics and Management, 40, 3-12.

Markusen, A., \& Schrock, G. (2006). The Distinctive City: An Occupational Approach. Book Manuscript, Project on Regional and Industrial Economics, the Humphrey Institute, University of Minnesota, January.

Peck, J. (2005). Struggling with the Creative Class. International Journal of Urban and Regional Research, 29, 740-770. https://doi.org/10.1111/j.1468-2427.2005.00620.x

Pei, L. L. (2018). Interactive Relationships between Talents Agglomeration and HighTech Industry Development. Studies in Science of Science, 36, 813-824.

Power, D. (2009). Priority Sector Report: Creative and Cultural Industries. European Commission, Publications Office of the European Union.

Rodríguez-Pose, A., \& Lee, N. (2020). Hipsters vs. Geeks? Creative Workers, Stem and Innovation in Us Cities. Cities, 100, Article ID: 102653. https://doi.org/10.1016/j.cities.2020.102653

Song, Z. Sh., Yang, S. L., \& Long, D. (2013). Empirical Research on the Relationship between Technological Innovation Talents and Economic Growth. Journal of Industrial Technological Economics, 32, 68-72.

Stolarick, K., \& Currid-Halkett, E. (2013). Creativity and the Crisis: The Impact of Creative Workers on Regional Unemployment. Cities, 33, 5-14.

https://doi.org/10.1016/j.cities.2012.05.017

Sun, S. (2012). Research on Computer-Based Creative Industries Development. Physics Procedia, 33, 1647-1651. https://doi.org/10.1016/j.phpro.2012.05.265

Tao, J., Ho, C. Y., Luo, S., \& Sheng, Y. (2019). Agglomeration Economies in Creative In- 
dustries. Regional Science and Urban Economics, 77, 141-154.

https://doi.org/10.1016/j.regsciurbeco.2019.04.002

Tiruneh, E. A. (2014). Regional Economic Development in Italy: Applying the Creative Class Thesis to a Test. Journal of the Knowledge Economy, 5, 19-36.

https://doi.org/10.1007/s13132-012-0126-3

UNCTAD (2010). Creative Economy. Report 2010. Geneva: UNCTAD.

Wang, M., Xuan, Y., \& Chen, Q. F. (2016). Creative Class Agglomeration, Knowledge Externalities and Urban Innovation-Evidence from 20 Large Cities. Economic Theory and Business Management, No. 1, 59-70.

Wang, Zh. (2014). The Capital Economic Circle of Financial Development and Industrial Structure Adjustment-An Empirical Study on the Inter Provincial Panel Data from 1978 to 2012. Economy and Management, 28, 90-97.

You, H., \& Bie, C. (2017). Creative Class Agglomeration across Time and Space in Knowledge City: Determinants and Their Relative Importance. Habitat International, 60, 91-100. https://doi.org/10.1016/j.habitatint.2016.12.010

Zhang, K. Y., \& Zhao, W. J. (2017). Regional Economic Growth, 3T Hypothesis and Creative Class Distribution: On System GMM Test of Inter-Provincial Panel Data. Journal of China University of Geosciences (Social Science Edition), 17, 117-127.

Zhang, S. B. (2011). The Relationship between Regional Agglomeration of Cultural and Creative Classes and Environmental Factors. Fujian Tribune, No. 10, 21-26.

Zhang, T. Q. (2008). Research on the Evaluation Index System of Talent Agglomeration Effect. Modern Management Science, No. 8, 83-84.

Zhao, K., Zhang, Y., Li, X. et al. (2020). Understanding Contributions of the Creative Class to Sustainable Economic Growth in China. Sustainability, 12, 1304.

https://doi.org/10.3390/su12041304

Zhao, Q. X., Xia, Ch. X., \& Shi, J. J. (2019). Sci-Tech Talents Agglomeration, Industry Agglomeration and Regional Innovation Capability: Empirical Analysis Based on JingJin-Ji Region, Yangtze River Delta and Pearl River Delta. Science and Technology Management Research, 39, 54-62. 